\title{
RESÍDUOS SÓLIDOS DA GASTRONOMIA: ESTUDO DE CASO EM UMA ESCOLA DE GASTRONOMIA
}

\author{
SOLID WASTE FROM GASTRONOMY: A CASE STUDY IN A SCHOOL OF \\ GASTRONOMY
}

\section{RESIDUOS SÓLIDOS DE LA GASTRONOMÍA: ESTUDIO DE CASO EN UNA ESCUELA DE GASTRONOMÍA}

\author{
Maria Pires Prates \\ Bolsista de Iniciação Científica CNPq Universidade de Caxias do Sul - UCS \\ Engenheira Ambiental pela UCS \\ mpprates@ucs.br \\ Orcid: https://orcid.org/0000-0001-5610-6603 \\ Suzana Maria De Conto \\ Docente no PPGTURH e PPGECAM na Universidade de Caxias do Sul - UCS \\ Doutora em Educação pela UFSCar \\ smcmande@ucs.br \\ Orcid: https://orcid.org/0000-0003-2680-9193
}

Data de submissão: 13/07/2017 - Data de aceite: 04/06/2018

\begin{abstract}
RESUMO: As pesquisas relacionadas à geração de resíduos sólidos e ao desperdício de alimentos são importantes para definir e integrar planos de gerenciamento desses resíduos na gestão de empreendimentos gastronômicos. Este estudo analisou a geração dos resíduos sólidos na Escola de Gastronomia da Universidade de Caxias do Sul. Foram realizadas observações diretas e caracterizações dos resíduos sólidos gerados na Escola durante sete semanas. Constatou-se que diferentes fatores influenciam na geração de resíduos e no desperdício de alimentos, destacando-se as particularidades das diferentes culinárias e dos ingredientes e o porcionamento das receitas. Conclui-se que a temática dos resíduos sólidos deve ser internalizada no serviço de alimentação e nas escolas de gastronomia, possibilitando aos alunos, aos professores e aos gestores refletir sobre o planejamento das atividades, movidos pela prevenção ou pela redução dos impactos ambientais decorrentes desse setor.
\end{abstract}

PALAVRAS-CHAVE: Resíduos Sólidos de Gastronomia; Desperdício de alimentos; Curso de Tecnologia em Gastronomia - UCS-RS.

ABSTRACT: Research on solid waste generation and food waste is important for defining and integrating waste management plans into the management of gastronomic enterprises. This study analyzes solid waste generation by the School of Gastronomy of the University of Caxias do Sul. Direct observations 
and characterizations of solid waste generated at the School were carried out over a period of seven weeks. It was observed that different factors influence the generation of waste and food waste, highlighting particularities of the different cuisines and ingredients, and the portions used in the recipes. It is concluded that solid waste should be internalized in the food service and gastronomy schools, allowing students, teachers and managers to reflect on the planning of activities, motivated by a desire to prevent or reduce the environmental impacts arising from this sector.

KEYWORDS: Gatronomy Solid Waste; Food Waste; Technical Higher Education in Gastronomy - UCS-RS.

RESUMEN: Las investigaciones relacionadas a la generación de residuos sólidos y al desperdicio de alimentos son importantes para definir e integrar planos de gerenciamiento de estos residuos en la gestión de emprendimientos gastronómicos. Este estudio analizó la generación de los residuos sólidos en la Escuela de Gastronomía de la Universidade de Caxias do Sul. Fueron realizadas observaciones directas y caracterizaciones de los residuos sólidos generados en la Escuela durante siete semanas. Se constató que diferentes factores influencian en la generación de residuos y al desperdicio de alimentos, se destacó las particularidades de las diferentes culinarias y de los ingredientes y la distribución de las recetas. Se concluyó que la temática de los residuos sólidos debe ser internalizada en el servicio de alimentación y en las escuelas de gastronomía, posibilitando a los alumnos, a los profesores y a los gestores reflexionar sobre la planificación de las actividades, movidos por la prevención o por la reducción de los impactos ambientales decurrentes de este sector.

PALABRAS CLAVE: Residuos Sólidos en la Gastronomía; Desperdicio de alimentos; Curso de Tecnología en Gastronomía - UCS-RS.

\section{INTRODUÇÃO}

O ramo gastronômico é responsável por variados impactos ambientais, decorrentes de diferentes aspectos, destacando-se o desperdício de recursos utilizados no cultivo, beneficiamento, distribuição, armazenamento e preparo dos alimentos. Destacam-se os desperdícios de água, de energia, de insumos, de embalagens, de agroquímicos, de extensões de terra, entre outros. Como decorrência do desperdício de alimentos, há a geração exacerbada de resíduos sólidos, a qual representa um problema de considerável relevância na gastronomia.

Uma forma de direcionar esforços para a minimização dos impactos ambientais, sociais e econômicos desses eventos é a inserção da temática da gestão de resíduos nos cursos de formação profissional relacionados à gastronomia. A Escola de Gastronomia da Universidade de Caxias do Sul (UCS), objeto de estudo deste trabalho, atua na formação de profissionais no campo da gastronomia (Universidade de Caxias do Sul, 2016).

Os impactos provocados pelo setor são assim replicados na atividade de ensino. Por esse motivo, verifica-se a necessidade de intervenções, de modo a amenizá-los e, consequentemente, contribuir com a construção de uma conduta ambientalmente responsável dos sujeitos envolvidos. Logo, ações voltadas ao diagnóstico da fonte geradora são necessárias para a tomada de decisão referente ao gerenciamento de resíduos oriundos desses empreendimentos.

Em vista disso, estudos de Krause e Bahls (2013) e Pistorello, De Conto e Zaro (2015) permitem entender a geração de resíduos sólidos em empreendimentos gastronômicos e as suas relações que são estabelecidas com a gastronomia sustentável. Cabe destacar que o diagnóstico da fonte geradora pode auxiliar na identificação de fatores que determinam a origem e a formação de resíduos sólidos, bem como o desperdício dos alimentos, possibilitando uma intervenção condizente no gerenciamento desses resíduos no âmbito dos serviços de gastronomia.

O objetivo geral deste estudoé analisar a geração de resíduos sólidos na Escola de Gastronomia da Universidade de Caxias do Sul. Como objetivos específicos há: caracterizar o empreendimento e suas principais atividades e serviços; determinar a composição gravimétrica e a geração per capita de resíduos sólidos; verificar como ocorre a segregação de resíduos sólidos; realizar o balanço mássico dos alimentos utilizados no preparo das 
receitas ministradas nas aulas práticas; e, por fim, analisar o aproveitamento/desperdício dos alimentos.

\section{RESÍDUOS SÓLIDOS E GASTRONOMIA}

No movimento contemporâneo de desenvolvimento do turismo, evidencia-se a consolidação da gastronomia como produto turístico (Almeida \& Hostins, 2011). As autoras discorrem que o turista procura conhecer aspectos da culinária local como estratégia de aproximação com a cultura da região. A partir da articulação da atividade turística com a oferta gastronômica, oferece-se a possibilidade de o turista estabelecer uma conexão com a história, a cultura e a população daquela localidade, permitindo-lhe uma espécie de "degustação" da realidade visitada (Gândara, 2009).

Em vista disso, a identidade gastronômica pode propiciar uma experiência gustativa diferenciada no contexto de hospitalidade (Gândara, 2009). Além do mais, Gândara (2009) destaca que o oferecimento de pratos típicos e/ ou regionais demonstra as relações de diplomacia entre visitante e visitado.

O ramo gastronômico, por envolver práticas intrínsecas à alimentação, perpassa aspectos de desenvolvimento econômico e cultural de um determinado local. Segundo Martínez (2012, p. 37), gastronomia "é o processo que engloba a culinária, a maneira de preparar os alimentos e as bebidas, bem como a matéria-prima usada para a elaboração dos pratos, além de todos os conhecimentos históricos e culturais de um respectivo lugar."

A difusão do conceito de sustentabilidade tem levado a sua incorporação junto à atividade gastronômica. Nessa direção, a NBR 15401 (Associação Brasileira de Normas Técnicas [ABNT], 2014), que estabelece os requisitos de implantação e operação do sistema de gestão de sustentabilidade em meios de hospedagem, evidencia a dimensão ambiental, social e econômica. Segundo a Norma, a sustentabilidade consiste no "uso dos recursos, de maneira ambientalmente responsável, socialmente justa e economicamente viável, de forma que $\mathrm{o}$ atendimento das necessidades atuais não comprometa a possibilidade de uso pelas futuras gerações." (ABNT, 2014, p. 5).
Krause e Bahls (2013) afirmam que os empreendimentos podem fidelizar clientes que prezam por atividades sustentáveis, que propagam ideias e atitudes condizentes com a atual situação ambiental e socioeconômica. Além disso, os proprietários assumem o papel de multiplicadores da consciência ambiental junto aos seus colaboradores e, estes, junto ao público (Marques, Lopes \& Claro, 2012).

Em relação ao planejamento dos cardápios, há o correto porcionamento dos pratos, o que, segundo Krause e Bahls (2013), otimiza o uso de recursos, gera maior rentabilidade ao negócio e diminui a geração de resíduos. Ademais, o uso da embalagem adequada, bem como o transporte e a estocagem apropriados contribuem para a minimização do desperdício e, consequentemente, dos custos e do impacto no meio ambiente (Krause \& Bahls, 2013).

Ainda, nesse contexto, o respeito à sazonalidade dos ingredientes evita o seu esgotamento, garantindo a sua disponibilidade e contribuição para o ecossistema que está inserido. Quanto ao uso de alimentos que representam valores culturais locais, além de diminuir o impacto relacionado ao transporte dos mesmos, fomenta o desenvolvimento cultural e econômico local (Krause \& Bahls, 2013).

No que tange aos meios de hospedagem, a NBR 15401 (ABNT, 2014) aplica os princípios da sustentabilidade junto à gastronomia a partir dos seguintes requisitos:

Os serviços de alimentação fornecidos pelo meio de hospedagem devem: a) adotar as boas práticas de segurança dos alimentos; b) utilizar preferencialmente produtos frescos; c) quando possível e viável economicamente, utilizar insumos da agricultura orgânica; d) incluir a oferta de alimentos e bebidas da sua culinária regional, respeitando a disponibilidade sazonal dos ingredientes, de maneira a não ameaçar a flora e a fauna. (ABNT, 2014, p. 25).

Krause e Bahls (2013) afirmam que, a partir do currículo permeado pela sustentabilidade, o profissional promoveráodesenvolvimentoeconômico sem deixar de visar aos aspectos socioambientais. Também afirmam que áreas acadêmicas distintas 
podem trabalhar em cooperação com a gastronomia, de modo a compartilhar conhecimentos, atingindo, assim, uma maior abrangência de atuação dentro da instituição de ensino.

A pesquisa realizada por Rubim (2012) investiga o consumo consciente e ético de alimentos em cursos de Tecnologia em Gastronomia, a partir de entrevistas com os coordenadores dos cursos. Rubim (2012) informa que foram poucos os que citaram a intenção de relacionar a sustentabilidade à preservação do patrimônio cultural gastronômico. Além disso, a autora alega que ações como parcerias com produtores; redução de embalagens; criação de um restaurante-escola; ou a implantação de um sistema de produção que envolva os alunos na obtenção do alimento, sequer foram mencionadas.

Com relação aos resíduos sólidos gerados nas atividades gastronômicas, cabe um destaque quanto aos princípios gerais, normativos e técnicos, no sentido de melhor contextualizar esse importante aspecto ambiental dessas atividades. Os resíduos sólidos são gerados como consequência das atividades humanas, podendo ser considerados como a parte indesejada resultante de um processo, ou seja, que não representa o produto final almejado. A Lei Federal n ${ }^{\mathrm{O}} 12305$ define resíduos sólidos e rejeitos:

resíduos sólidos: material, substância, objeto ou bem descartado resultante de atividades humanas em sociedade, a cuja destinação final se procede, se propõe proceder ou se está obrigado a proceder, nos estados sólido ou semissólido, bem como gases contidos em recipientes e líquidos cujas particularidades tornem inviável o seu lançamento na rede pública de esgotos ou em corpos d'água, ou exijam para isso soluções técnica ou economicamente inviáveis em face da melhor tecnologia disponível.

rejeitos: resíduos sólidos que, depois de esgotadas todas as possibilidades de tratamento e recuperação por processos tecnológicos disponíveis e economicamente viáveis, não apresentem outra possibilidade que não a disposição final ambientalmente adequada. (Brasil, 2010).

A Política Nacional de Resíduos Sólidos (PNRS) dispõe sobre seus princípios, objetivos e instrumentos (Brasil, 2010). Segundo a Lei: gerenciamento de resíduos sólidos: conjunto de ações exercidas, direta ou indiretamente, nas etapas de coleta, transporte, transbordo, tratamento e destinação final ambientalmente adequada dos resíduos sólidos e disposição final ambientalmente adequada dos rejeitos, de acordo com plano municipal de gestão integrada de resíduos sólidos ou com plano de gerenciamento de resíduos sólidos exigidos na forma desta Lei.

gestão integrada de resíduos sólidos: conjunto de ações voltadas para a busca de soluções para os resíduos sólidos, de forma a considerar as dimensões política, econômica, ambiental, cultural e social, com controle social e sob a premissa do desenvolvimento sustentável. (Brasil, 2010).

A NBR 10004 classifica os resíduos sólidos quanto à sua periculosidade ao meio ambiente $\mathrm{e}$ à saúde pública (Associação Brasileira de Normas Técnicas, 2004). Além disso, a PNRS os classifica quanto à origem (Brasil, 2010), sendo que os resíduos sólidos da gastronomia são classificados como resíduos de estabelecimentos comerciais e de prestação de serviços. O Art. $1^{\mathrm{o}}$ da Lei 12305 determina que:

Estão sujeitas à observância desta Lei as pessoas físicas ou jurídicas, de direito público ou privado, responsáveis, direta ou indiretamente, pela geração de resíduos sólidos e as que desenvolvam ações relacionadas à gestão integrada ou ao gerenciamento de resíduos sólidos. (Brasil, 2010).

Portanto, os empreendimentos gastronômicos são responsáveis pela gestão dos resíduos sólidos oriundos de suas atividades, devendo observar a seguinte ordem de prioridade nas etapas de gerenciamento: não geração, redução, reutilização, reciclagem, tratamento dos resíduos sólidos e disposição final ambientalmente adequada dos rejeitos (Brasil, 2010).

Em relação à legislação específica imposta aos estabelecimentos gastronômicos, estão as práticas sanitárias, as quais, segundo Mezomo (2015), são representadas pelo conjunto de medidas que devem ser adotadas, a fim de impedir a contaminação, deterioração ou adulteração de um alimento. Nessa direção há a RDC nº 216 (Agência 
Nacional de Vigilância Sanitária [ANVISA], 2004), a qual institui que tais estabelecimentos devem dispor de Manual de Boas Práticas. Quanto ao manejo de resíduos, a mesma estabelece que:

O estabelecimento deve dispor de recipientes identificados e íntegros, de fácil higienização e transporte, em número e capacidade suficientes para conter os resíduos; os coletores utilizados para deposição dos resíduos das áreas de preparação e armazenamento de alimentos devem ser dotados de tampas acionadas sem contato manual; os resíduos devem ser frequentemente coletados e estocados em local fechado e isolado da área de preparação e armazenamento dos alimentos, de forma a evitar focos de contaminação e atração de vetores e pragas urbanas. (ANVISA, 2004).

Levantamentos sobre a geração de resíduos sólidos em restaurantes são necessários para a gestão gastronômica (Pistorello et al., 2015). Ou seja, a aquisição, o consumo e a geração dos resíduos devem ser investigados concomitantemente, para promover o entendimento de como, onde e por que o resíduo de alimento é gerado (Papargyropoulou et al., 2016).

A caracterização dos resíduos sólidos representa uma ferramenta de planejamento do manejo dos resíduos, por permitir a identificação da origem e dos fatores que interferem na sua geração (Peruchin, Ferrão, Guidoni, Corrêa, \& Corrêa, 2015). A determinação da composição gravimétrica dos resíduos está entre as principais formas de caracterizá-los, pois, de acordo com Monteiro et al. (2001), a mesma traduz o percentual de cada componente em relação à massa total da amostra de resíduos analisada.

A partir do balanço mássico, Pistorello et al. (2015) explanam que é possível identificar a quantidade de alimentos empregados no preparo, os resíduos gerados durante o preparo e após o consumo. Partindo-se dessa etapa, os mesmos afirmam que se possibilita a proposição de medidas preventivas de geração de resíduos e/ou de reaproveitamento de alimentos.

Para Bradacz (2003), o desperdício ocorre devido a fatores como: rotatividade dos funcionários, problemas com equipamentos de manipulação dos alimentos, compras feitas sem critérios e falta de indicadores de qualidade do serviço prestado. Além disso, Pirani e Arafat (2014) afirmam que, quanto maior a variedade de pratos servidos, tende-se a gerar mais resíduos e o experimento de novas receitas pode levar ao aumento da geração, como no caso de a mesma ser descartada quando não satisfatória.

O estudo de Pistorello et al. (2015) foi desenvolvido no restaurante de um hotel. Os pesquisadores coletaram dados durante períodos de alta e baixa temporada, caracterizados pela ocorrência ou não de eventos na região. Os autores constataram que, nos coffee-breaks, há o maior índice de alimentos consumidos com base na quantidade de alimentos ofertados $(84,3 \%) \mathrm{em}$ comparação com as outras refeições servidas.

Também nesse estudo, foi constatado que a maior parcela dos resíduos sólidos gerados no restaurante refere-se à matéria orgânica putrescível, variando de 84,1 a 92,7\%. Já Peruchin, Guidoni, Corrêa e Corrêa (2013) investigaram a composição gravimétrica dos resíduos gerados em um restaurante universitário, cuja matéria orgânica corresponde a 82,14\%; materiais poliméricos $(7,80 \%)$ e contaminantes biológicos $(4,60 \%)$. Em relação à contribuição dos clientes, Pistorello et al. (2015) mostram que a geração per capita na alta temporada foi de 204,7 g de resíduos sólidos/ refeição e, na baixa temporada, foi de 161,8 g/refeição. Nessa situação, Peruchin et al. (2013) verificaram que esse índice variou entre 99 e 186 g/refeição.

Nessa direção, Teixeira, Milet, Carvalho e Biscontini (2007) afirmam que a avaliação diária das sobras é uma medida que pode ser utilizada no controle operacional do estabelecimento, sendo que, na fase de planejamento, deve ser definida uma margem de segurança. A autora discorre que o excesso de sobras pode denotar falhas no porcionamento ou no planejamento das refeições. Além disso, Pirani e Arafat (2014) alegam que os estabelecimentos devem se assegurar que estão sendo servidas porções grandes o suficiente para satisfazer o cliente, mas não tão fartas de modo a induzir o desperdício.

Tatàno, Caramiello, Paolini e Tripolone (2017) conduziram um estudo de caso em um restaurante situado na área costeira turística da Itália. Segundo os autores, a geração de resíduos pode ser minimizada no restaurante estudado pelos seguintes fatores: promoção do uso da comida local; padronização e limitação dos itens do cardápio diário; e consolidação das receitas e do conhecimento e da experiência das práticas culinárias. 
Nesse contexto, em relação à prevenção da geração de resíduos sólidos, Pirani e Arafat (2016) afirmam que muitos dos hotéis que integraram sua pesquisa adotavam procedimentos para minimizar o descarte de alimentos devido à deterioração ou à perda da validade. Entre esses, consta: utilizar antes os insumos adquiridos há mais tempo; planejar os pratos usando os ingredientes que irão expirar brevemente; e armazenar as frutas e os vegetais em embalagens que promovam a circulação do ar, reduzindo o desenvolvimento microbiano e a deterioração.

O tipo de serviço também pode influenciar os índices de desperdício. Por exemplo, o denominado buffet livre pode induzir os consumidores a se servirem mais do que irão consumir. Já nas refeições à la carte, os alimentos são preparados conforme a demanda, fazendo com que não haja alimentos preparados e não ofertados (Pistorello et al., 2015).

Outro destaque importante de Pirani e Arafat (2014) está relacionado a outro fator que contribui para a geração de resíduos: a previsão da demanda de consumo. O mesmo depende do conhecimento do padrão de consumo dos clientes e da previsão do número de público (Pirani \& Arafat, 2016). Os autores continuam destacando que, enquanto os estabelecimentos temem pela falta de comida para suprir a demanda do cliente, risco que muitos não estão dispostos a correr, preferindo cozinhar um percentual extra de comida por segurança.

Em relação à instrução dos funcionários sobre como manejar os resíduos, Corrêa e Lange (2011) relatam que há falta de atenção dos mesmos em relação à correta segregação e ao acondicionamento. Bradacz (2003) também observa que os desperdícios aumentam em períodos de contratação de mão de obra temporária, que não recebeu capacitação e conscientização de maneira adequada. Além disso, a redução da eficiência da segregação e o aumento da geração de resíduos podem ser esperados em períodos em que os funcionários estão submetidos à pressão em termos do número de refeições servidas e o encerramento da temporada turística no local em que o restaurante se insere (Tatàno et al., 2017).

Já De Conto, Corrêa e Zaro (2013) esclarecem a importância da sistematização da fonte geradora de resíduos para a definição do espaço para o manejo dos mesmos. Os autores destacam a necessidade de contemplar no projeto arquitetônico o espaço para o armazenamento provisório de todos os resíduos gerados nas edificações, em especial em meios de hospedagens (objeto de estudo).

As práticas sustentáveis em empreendimentos gastronômicos podem se basear nos conceitos da Produção mais Limpa $(\mathrm{P}+\mathrm{L})$. De acordo com o Centro Nacional de Tecnologias Limpas (CNTL, 2003),

Produção mais Limpa é a aplicação de uma estratégia técnica, econômica e ambiental integrada aos processos e produtos, a fim de aumentar a eficiência no uso de matérias-primas, água e energia, através da não geração, minimização ou reciclagem dos resíduos e emissões geradas, com benefícios ambientais, de saúde ocupacional e econômicos. (CNTL, 2003).

A adoção da Produção mais Limpa resulta na eficiência global do processo produtivo, por meio de: eliminação dos desperdícios; minimização ou eliminação de matériasprimas e outros insumos impactantes para o meio ambiente; redução dos resíduos e emissões; redução dos custos de gerenciamento dos resíduos; minimização dos passivos ambientais; incremento na saúde e segurança no trabalho. (CNTL, 2003).

Logo, a P $+\mathrm{L}$ também contribui para melhorar a imagem da empresa, aumentar a produtividade, instituir a conscientização ambiental dos funcionários, reduzir os custos, entre outros (CNTL, 2003).

Um item importante, quando se está listando a quantidade de alimentos necessários para preparar uma refeição, é a perda que esses irão sofrer ao serem manipulados, como por retirada das cascas, sementes, pele e ossos (Teichmann, 2009). Logo, deve ser feita uma correção, por meio do Fator de Correção (F.C.), o qual é multiplicado pela quantidade necessária a ser servida, permitindo obter a quantidade necessária para aquisição (Teichmann, 2009). A autora afirma que esses cálculos podem ser realizados na cozinha, buscando uma relação real, ou ainda se pode usar tabelas prontas que fornecem valores médios.

Considerando que a informação é uma variável que determina o comportamento das pessoas em relação ao manejo de resíduos sólidos, 
é importante que a mesma seja de qualidade e disponibilizada de forma contínua (Mandelli, 1997; De Conto, 2010). Em vista disso, a adoção de uma engenharia comportamental favorece a construção de condições para mudança ou aperfeiçoamento de comportamentos em relação à geração e no manejo de resíduos (De Conto, 2010), empregando-se recursos que conduzem o indivíduo a avaliar suas práticas e alterar ou fortalecer certas condutas (Mandelli, 1997). Parafraseando De Conto (2010), constata-se que lidar com resíduos oriundos do serviço de alimentação exige um esforço integrado e o comprometimento de todos os atores envolvidos, no sentido de minimizar os impactos ambientais decorrentes do setor gastronômico.

\section{METODOLOGIA}

A pesquisa é classificada como exploratóriodescritiva. Segundo Köche (2013), a pesquisa exploratória envolve um processo de investigação que identifica a natureza do fenômeno e a presença de variáveis, com o objetivo de descrevê-las ou caracterizá-las. A pesquisa descritiva, segundo o mesmo autor, estuda as relações entre duas ou mais variáveis de um dado fenômeno sem manipulá-las. Köche (2013) também destaca que a pesquisa descritiva constata e avalia relações entre as variáveis à medida que as mesmas se manifestam espontaneamente em fatos, situações e nas condições que já existem.

Trata-se de um estudo de caso, com a realização de observação direta nos diferentes setores geradores de resíduos e caracterização física desses resíduos. De acordo com Marconi e Lakatos (2011), o estudo de caso consiste no levantamento com profundidade de determinada conjuntura, se restringindo ao caso que estuda. Já a observação direta é uma técnica de coleta de dados que visa ao registro de informações, a partir da percepção de determinados aspectos, examinando os fenômenos que se deseja estudar (Marconi \& Lakatos, 2008).

A pesquisa foi conduzida na Escola de Gastronomia da Universidade de Caxias do Sul (UCS), que está localizada na Serra Gaúcha, no município de Flores da Cunha, RS. Inaugurada em 2004, a Escola foi criada com a missão institucional de difundir a cultura do gosto e da gastronomia italiana, em parceria com o Italian Culinary Institute for Foreigners (ICIF), ao articular o ensino nos níveis de graduação, extensão, pós-graduação e ensino técnico (Universidade de Caxias do Sul, 2016).

As atividades oferecidas pela Escola de Gastronomia e que foram abrangidas no estudo são as seguintes: Chef de Cozinha Internacional (curso de capacitação profissional, denominado como "Chef"); Curso Técnico em Gastronomia (integra as turmas do ensino médio do Centro Tecnológico Universidade de Caxias do Sul CETEC); Coffee-breaks (prestação de serviços para eventos externos, denominado como coffees) e Tecnologia em Gastronomia (curso superior que visa à formação de profissionais aptos em termos de concepção e gerenciamento de produções culinárias) (Universidade de Caxias do Sul, 2014).

A partir da observação direta, constatouse que o empreendimento possui os seguintes setores: Cozinha de demonstração; Cozinha didática; Panificação e Confeitaria; Cozinha fria; Enoteca; Restaurante com cozinha própria; Copa; Administrativo; Lavanderia; vestiários e sanitários. Nos espaços onde ocorrem o preparo dos alimentos e/ou as aulas práticas, há dois dispositivos de acondicionamento de resíduos, um para os orgânicos e outro para os recicláveis.

A coleta interna dos resíduos sólidos é realizada após cada aula, no momento da limpeza do setor. Os resíduos são transferidos para dois contêineres: um verde para o orgânico e rejeitos e um amarelo para os recicláveis, ambos disponibilizadas pelo Poder Público Municipal. A coleta de resíduos orgânicos, rejeitos e seletivos é realizada nas segundas, quartas e sextas-feiras pela manhã.

A coleta e o transporte dos resíduos sólidos domiciliares são realizados por uma empresa terceirizada, contratada pelo município, os quais são conduzidos até a estação de transbordo do município, onde funciona uma central de triagem que separa os resíduos recicláveis (Flores da Cunha, 2014). Após a triagem, a empresa faz o recolhimento dos resíduos orgânicos e rejeitos, encaminhando-os ao aterro sanitário, localizada no município de Minas do Leão, distante $240 \mathrm{~km}$ de Flores da Cunha (Flores da Cunha, 2014).

A caracterização dos resíduos sólidos gerados na Escola consistiu na determinação da composição gravimétrica. Foram estipulados dois períodos de amostragem para teste (novembro e outro em novembro e dezembro de 2016), seguidos de cinco semanas de amostragem durante o calendário letivo (março e abril de 2017). 
Durante o período de teste, foram caracterizados os resíduos sólidos gerados em todos os setores da Escola, correspondendo ao resíduo gerado em cada semana (manhã, tarde e noite de quarta-feira e manhã e tarde de quintafeira). Todos os sacos que acondicionavam os resíduos foram etiquetados com identificação do setor, turno da atividade e data.

Após devidamente acondicionados e etiquetados, os resíduos foram transferidos para o local coberto designado para a caracterização. Os mesmos foram dispostos sobre uma lona plástica para a separação e pesagem dos diferentes componentes. Após a caracterização, os resíduos foram transferidos para os contêineres externos da Escola.

Os resíduos foram separados em categorias propostas por De Conto, Pessin, Pistorello, Zaro e Poletto (2009): matéria orgânica putrescível, plástico, papel e papelão, vidro, metal ferroso, metal não ferroso, madeira, panos, trapos, couro e borracha, contaminante químico, contaminante biológico, pedra, terra e cerâmica, misto e diversos.

Após o estabelecimento das situações de geração de resíduos no empreendimento, foram selecionadas duas disciplinas práticas do curso de Tecnologia em Gastronomia para compor as amostragens: Confeitaria e Cozinha das Américas. As mesmas foram escolhidas por representar culinárias variadas em relação a ingredientes e pratos. As informações coletadas durante as aulas foram as seguintes: receitas ministradas, lista de insumos utilizados, número de alunos presentes, além do número de grupos de alunos que preparavam as receitas.

Os resíduos foram coletados após cada aula, sendo a caracterização realizada seguindo os mesmos procedimentos adotados no período de teste. Além disso, foi calculada a geração per capita de resíduos de cada uma das situações, obtida a partir da massa de resíduos gerada dividida pelo número de alunos presentes na respectiva aula. Tal valor foi determinado com o intuito de identificar possíveis relações entre a geração de resíduos, o número de alunos e grupos presentes nas aulas e o número e tipo de receitas culinárias.

A composição gravimétrica dos resíduos acondicionados nos contêineres orgânico e seletivo foi analisada separadamente. Para a realização do balanço mássico das aulas práticas, foram considerados: alimentos utilizados no preparo dos pratos; resíduos gerados no preparo durante as aulas;

pratos que não foram consumidos pelos alunos no momento de degustação (a degustação ocorre após o encerramento das aulas), mas foram guardados e pratos descartados. Todos os dados coletados (massa dos diferentes componentes de resíduos sólidos) foram organizados em planilhas em Excel, obedecendo ao método de quantificação proposto por De Conto et al. (2009). Posteriormente, os dados foram organizados em tabelas.

\section{RESULTADOS}

Apresentam-se os resultados obtidos por meio da caracterização dos resíduos sólidos. Primeiramente são apresentados os resultados correspondentes ao período de teste. Posteriormente são apresentados os resultados relativos ao período de amostragem das disciplinas do curso de Tecnologia em Gastronomia selecionadas na pesquisa.

\section{PERÍODO DE TESTE}

Em relação ao período de teste, apresenta-se a análise da geração de resíduos sólidos orgânicos e seletivos das duas semanas de estudo em 2016. O Quadro 1 apresenta os dados de composição gravimétrica dos resíduos sólidos gerados durante o referido período.

Quadro 1 - Composição gravimétrica dos resíduos sólidos referente ao período de teste

\begin{tabular}{|c|c|c|}
\hline CATEGORIAS & $\begin{array}{c}\text { MASSA } \\
(\mathbf{k g})\end{array}$ & $\mathbf{\%}$ \\
\hline $\begin{array}{c}\text { Matéria orgânica } \\
\text { putrescível }\end{array}$ & 117,322 & 79,00 \\
\hline Plástico & 17,263 & 11,62 \\
\hline Papel e papelão & 3,709 & 2,50 \\
\hline Vidro & 0,386 & 0,26 \\
\hline Metal ferroso & 0,544 & 0,37 \\
\hline Metal não ferroso & 0,150 & 0,10 \\
\hline Madeira & 0,040 & 0,03 \\
\hline $\begin{array}{c}\text { Pano, trapo, couro e } \\
\text { borracha }\end{array}$ & 2,972 & 2,00 \\
\hline Contaminante biológico & 3,526 & 2,37 \\
\hline Contaminante químico & 0,006 & 0,00 \\
\hline Pedra, terra e cerâmica & 0,000 & 0,00 \\
\hline Misto & 2,510 & 1,69 \\
\hline Diversos & 0,076 & 0,05 \\
\hline TOTAL & 148,504 & 100,00 \\
\hline
\end{tabular}

Fonte: As autoras (2016). 
Durante a caracterização, foram encontradas embalagens de recheios de salgados descartados junto aos resíduos seletivos. Analisando-se os resíduos seletivos e os plásticos depositados junto aos resíduos orgânicos, verificaram-se problemas na segregação, bem como o consumo demasiado de copos plásticos durante as aulas práticas.

Constatou-se o descarte de quatro pacotes inteiros de pão de forma fora de prazo de validade. Durante o preparo dos coffees, houve o descarte de $8,325 \mathrm{~kg}$ de massas vencidas lacradas. Também se evidenciou a mistura de resíduo orgânico junto ao seletivo, devido à presença de guardanapos impregnados, panos de limpeza e palitos de churrasco.

Visto que os dois períodos corresponderam ao resíduo gerado em um dia e meio por semana, constatou-se que a massa total é $148,504 \mathrm{~kg}$, ou seja, 49,502 kg/dia. A categoria de maior geração foi a matéria orgânica putrescível (79\%), seguido do plástico $(11,62 \%)$ e papel e papelão $(2,50 \%)$.

Ressalta-se que, em algumas situações, identificou-se o desperdício de alimentos, alguns identificados como inválidos. Também foi observado que o procedimento de separar e dosar os ingredientes em copos e sacos plásticos durante as aulas práticas resultou no consumo e, consequentemente, no descarte desses materiais em uma quantidade significativa.

\section{PERÍODO DE AMOSTRAGENS DE RESÍDUOS SÓLIDOS DAS DISCIPLINAS: COZINHA DAS AMÉRICAS E CONFEITARIA}

Com relação à amostragem realizada durante cinco semanas no período março-abril, apresentase a análise da geração de resíduos sólidos da Cozinha das Américas e Confeitaria.

$\mathrm{Na}$ disciplina de Cozinha das Américas, cada aula é relativa a um país do continente americano. O professor responsável inicia as atividades explanando sobre a culinária do país. Os alunos, divididos em cinco ou seis grupos, prepararam as receitas. Cada grupo ocupava uma bancada da cozinha didática, sendo os ingredientes divididos entre os grupos. Os alunos utilizavam uma balança para a pesagem de ingredientes, sendo utilizados copos plásticos para acondicioná-los durante a pesagem.

Aproximadamente 20 minutos antes do término da aula, o funcionário responsável pela cozinha recolhia os insumos não utilizados. Os insumos possíveis de aproveitamento eram armazenados novamente na cozinha. Os pratos eram consumidos durante ou no término da aula e as sobras descartadas. Cabe destacar que os resíduos caracterizados são resultantes do preparo dos alimentos e restos dos pratos após o consumo da degustação.

A Tabela 1 apresenta os dados da caracterização dos resíduos sólidos gerados nas aulas práticas de Cozinha das Américas.

Tabela 1 - Composição gravimétrica e geração per capita de resíduos sólidos gerados nas aulas práticas de Cozinha das Américas

\begin{tabular}{|c|c|c|c|c|c|c|c|c|c|c|c|c|}
\hline \multirow{2}{*}{$\begin{array}{l}\text { CATE- } \\
\text { GORIAS }\end{array}$} & \multicolumn{2}{|c|}{ Dia $1(20 / 3)$} & \multicolumn{2}{|c|}{ Dia $2(03 / 4)$} & \multicolumn{2}{|c|}{ Dia $3(10 / 4)$} & \multicolumn{2}{|c|}{ Dia $4(17 / 4)$} & \multicolumn{2}{|c|}{ Dia $5(24 / 4)$} & \multicolumn{2}{|c|}{ TOTAL } \\
\hline & kg & $\%$ & $\mathrm{~kg}$ & $\%$ & $\mathrm{~kg}$ & $\%$ & $\mathrm{~kg}$ & $\%$ & $\mathrm{~kg}$ & $\%$ & $\mathrm{~kg}$ & $\%$ \\
\hline $\begin{array}{c}\text { Matéria } \\
\text { orgânica } \\
\text { putrescível }\end{array}$ & 11,982 & 94,74 & 8,280 & 87,29 & 9,050 & 83,36 & 13,084 & 92,23 & 20,014 & 93,65 & 62,410 & 91,05 \\
\hline Plástico & 0,606 & 4,79 & 0,446 & 4,70 & 0,546 & 5,03 & 0,450 & 3,17 & 0,568 & 2,66 & 2,616 & 3,82 \\
\hline $\begin{array}{l}\text { Papel e } \\
\text { papelão }\end{array}$ & 0,016 & 0,13 & 0,002 & 0,02 & 0,014 & 0,13 & 0,016 & 0,11 & 0,032 & 0,15 & 0,080 & 0,12 \\
\hline Vidro & - & - & - & - & 0,612 & 5,64 & - & - & - & - & 0,612 & 0,89 \\
\hline $\begin{array}{l}\text { Metal não } \\
\text { ferroso }\end{array}$ & - & - & - & - & 0,114 & 1,05 & 0,016 & 0,11 & 0,020 & 0,09 & 0,150 & 0,22 \\
\hline
\end{tabular}




\begin{tabular}{|c|c|c|c|c|c|c|c|c|c|c|c|c|}
\hline Madeira & 0,036 & 0,28 & - & - & - & - & - & - & - & - & 0,036 & 0,05 \\
\hline $\begin{array}{c}\text { Pano, } \\
\text { trapo, } \\
\text { couro e } \\
\text { borracha }\end{array}$ & 0,007 & 0,05 & 0,634 & 6,68 & 0,458 & 4,22 & 0,560 & 3,95 & 0,484 & 2,26 & 2,143 & 3,13 \\
\hline $\begin{array}{c}\text { Pedra, } \\
\text { terra e } \\
\text { cerâmica }\end{array}$ & - & - & - & - & 0,042 & 0,39 & - & - & - & - & 0,042 & 0,06 \\
\hline Misto & - & - & 0,124 & 1,31 & 0,020 & 0,18 & 0,060 & 0,42 & 0,252 & 1,18 & 0,456 & 0,67 \\
\hline TOTAL & 12,647 & 100 & 9,486 & 100 & 10,856 & 100 & 14,186 & 100 & 21,370 & 100 & 68,545 & 100 \\
\hline $\begin{array}{l}\text { Número } \\
\text { de alunos } \\
\text { presentes }\end{array}$ & 17 & - & 18 & - & 19 & - & 19 & - & 20 & - & 93 & - \\
\hline $\begin{array}{c}\text { Geração } \\
\text { per capita } \\
\text { (kg/aluno. } \\
\text { aula) }\end{array}$ & 0,744 & - & 0,527 & - & 0,571 & - & 0,747 & - & 1,069 & - & 0,737 & - \\
\hline
\end{tabular}

Fonte: As autoras (2017).

Nos cinco períodos de amostragem, foi gerado um total de $68,545 \mathrm{~kg}$ de resíduos sólidos. A maior parte dos resíduos consiste de restos alimentares, identificados como matéria orgânica putrescível (91,05\%), seguido de plástico $(3,82 \%)$ e pano, trapo, couro e borracha (3,13\%). No dia $24 / 04$ houve a maior geração de resíduos orgânicos, enquanto a menor geração foi registrada em 03/04. No dia 10/04, o percentual da representação do resíduo orgânico foi inferior. Constatou-se nessa amostra a presença de uma garrafa de vidro, que contribuiu para o aparecimento da categoria vidro.

Em relação à geração per capita de resíduos sólidos, a mesma variou entre 0,527 a $1,069 \mathrm{~kg} /$ aluno.aula, representando uma média de 0,737 $\mathrm{kg} /$ aluno.aula. Relacionando esses resultados com o número de alunos presentes, percebeu-se que a relação entre essas variáveis não é linear, considerando o desenvolvimento das atividades em grupos. Além disso, as especificidades dos pratos preparados em cada aula podem configurarse como um fator condicionante da geração de resíduos sólidos.

Em relação aos resíduos sólidos que se encontravam acondicionados nos dispositivos distribuídos nas cozinhas para resíduo orgânico, observou-se que 95,49\% dos resíduos representavam matéria orgânica putrescível, sendo constatada a mistura de materiais considerados recicláveis (plástico, 1,45\%; papel e papelão, $0,05 \%$; e metal não ferroso, 0,14\%). Alguns componentes estavam impregnados com alimento, enquanto outros apresentavam condições ideais de reciclabilidade. Já entre os resíduos sólidos que se encontravam acondicionados nos dispositivos para resíduo seletivo, verificou-se que a presença da matéria orgânica putrescível $(36,89 \%)$ era superior ao plástico $(32,66 \%)$ e aos outros materiais (vidro, $11,77 \%$; misto, $8,04 \%$ e metal não ferroso, 1,23\%). Essa constatação evidencia a falha na segregação correta dos resíduos pelos alunos.

O Quadro 2 apresenta os exemplos de componentes observados nas caracterizações dos resíduos sólidos gerados nas aulas de Cozinha das Américas, sendo possível observar quais resíduos foram acondicionados erroneamente. Constatouse que guardanapos impregnados com alimento e restos alimentares estavam presentes nos contêineres de resíduo seletivo.

A quantidade de insumos necessária para cada aula é calculada pela Escola a partir do rendimento de cada receita que será desenvolvida na cozinha. A quantidade de insumos é definida pelo professor, considerando o número de alunos matriculados na disciplina. No entanto, pela observação direta, evidencia-se que a quantidade de sobras ainda foi significativa. Logo, presume-se que haja outros fatores determinantes relacionados com a quantidade de ingredientes não utilizados durante as aulas.

A aula de 20/03 demandou o maior consumo de insumos, visto que a aula trabalhou com o maior número de receitas (sete). Entretanto, verifica-se que não há proporcionalidade entre o número de receitas, a massa de ingredientes fornecidos e os ingredientes não utilizados, o que evidencia a influência das particularidades dos ingredientes 
e do porcionamento das receitas. O percentual do insumo fornecido em cada aula prática que foi convertido em resíduo variou de 27,24 a $57,93 \%$, representando uma média de $41,15 \%$. O número pode ser considerado bem expressivo, pois de $166,558 \mathrm{~kg}$ de ingredientes fornecidos, $68,545 \mathrm{~kg}$ foram descartados como resíduo de preparo ou como prato não consumido.

Quadro 2 - Exemplos de componentes de resíduos sólidos observados nas aulas de Cozinha das Américas

\begin{tabular}{|c|c|c|}
\hline \multirow{2}{*}{ CATEGORIAS } & \multicolumn{2}{|c|}{ Exemplos observados } \\
\hline & Contêiner orgânico & Contêiner seletivo \\
\hline $\begin{array}{l}\text { Matéria orgânica } \\
\text { putrescível }\end{array}$ & $\begin{array}{c}\text { Guardanapos impregnados com } \\
\text { alimento, salsa, milho, camarão, polvo, } \\
\text { aipim, feijão, cascas (de ovo, de cebola } \\
\text { e de banana), massa crua, abóbora, } \\
\text { clara de ovo, palha de milho, sabugo, } \\
\text { limão, arroz, frango cru e frito, porco } \\
\text { assado, casca e coroa de abacaxi, garras } \\
\text { de lagostinho, mexilhão, carne picada, } \\
\text { anéis de lula, chuchu, tomate, pimentão, } \\
\text { pedaços de peixe, batata, pimenta e } \\
\text { temperos }\end{array}$ & $\begin{array}{l}\text { Guardanapos impregnados com alimentos, } \\
\text { alecrim, alho, cebola, tomate, cascas (de ovo, } \\
\text { de cebola), pedaço de camarão, cebola, chuchu, } \\
\text { queijo, banana e temperos }\end{array}$ \\
\hline Plástico & $\begin{array}{c}\text { Sacos e copos plásticos; embalagens (de } \\
\text { peito de frango, de goiabada, de óleo, } \\
\text { de filé de frango, de copos) e bandeja de } \\
\text { isopor }\end{array}$ & $\begin{array}{c}\text { Sacos e copos plásticos, bandeja de isopor, } \\
\text { embalagens (de óleo, de molho inglês, de } \\
\text { copos, de mandioquinha, de queijo minas, } \\
\text { de óleo, de creme de leite, de chocolate) } \\
\text { embalagem plástica e plástico bolha com fita } \\
\text { adesiva }\end{array}$ \\
\hline Papel e papelão & Papel A4 & Caixa de papelão, papel A4 e folha de caderno \\
\hline Vidro & - & Garrafa de rum \\
\hline Metal não ferroso & Papel alumínio & $\begin{array}{c}\text { Fios de cobre, papel alumínio e lata de } \\
\text { refrigerante }\end{array}$ \\
\hline Madeira & Palitos de churrasco & Palitos de churrasco \\
\hline $\begin{array}{l}\text { Pano, trapo, } \\
\text { couro e borracha }\end{array}$ & Panos de limpeza & $\begin{array}{l}\text { Panos de limpeza, luva, máscara e borracha } \\
\text { preta }\end{array}$ \\
\hline $\begin{array}{l}\text { Pedra, terra e } \\
\text { cerâmica }\end{array}$ & - & Colher de porcelana \\
\hline Misto & Embalagem de manteiga & $\begin{array}{c}\text { Embalagens (de manteiga, de biscoitos, de } \\
\text { milho em conserva, de faca e de barra cereal) e } \\
\text { caixas de leite }\end{array}$ \\
\hline
\end{tabular}

Fonte: As autoras (2017).

$\mathrm{Na}$ disciplina de Confeitaria, como ocorre nas aulas de Cozinha das Américas, há uma breve explanação no início de cada aula feita pela professora. Após isso, os alunos eram divididos em grupos conforme o número de receitas e a quantidade das porções. Destaca-se que as receitas demonstrativas eram preparadas somente pela professora.

No final da aula era proporcionado o momento da degustação, na qual o alimento não consumido era distribuído aos alunos das outras turmas durante a troca de turno das aulas. Quando os alimentos não eram totalmente consumidos, os mesmos eram encaminhados à cozinha, podendo ser consumidos momentaneamente pelos funcionários ou descartados. A Tabela 2 apresenta os dados da caracterização dos resíduos sólidos gerados nas aulas práticas de Confeitaria. 
Tabela 2 - Composição gravimétrica e geração per capita de resíduos sólidos gerados nas aulas práticas de Confeitaria

\begin{tabular}{|c|c|c|c|c|c|c|c|c|c|c|c|c|}
\hline \multirow{2}{*}{ CATEGORIAS } & \multicolumn{2}{|c|}{ Dia $1(20 / 3)$} & \multicolumn{2}{|c|}{ Dia $2(03 / 4)$} & \multicolumn{2}{|c|}{ Dia $3(10 / 4)$} & \multicolumn{2}{|c|}{ Dia 4 (17/4) } & \multicolumn{2}{|c|}{ Dia $5(24 / 4)$} & \multicolumn{2}{|c|}{ TOTAL } \\
\hline & $\mathrm{kg}$ & $\%$ & $\mathrm{Kg}$ & $\%$ & $\mathrm{~kg}$ & $\%$ & $\mathrm{Kg}$ & $\%$ & $\mathrm{~kg}$ & $\%$ & $\mathrm{~kg}$ & $\%$ \\
\hline $\begin{array}{c}\text { Matéria orgânica } \\
\text { putrescível }\end{array}$ & 2,718 & 86,01 & 4,024 & 73,43 & 3,876 & 74,71 & 3,120 & 77,42 & 3,040 & 78,11 & 16,778 & 77,14 \\
\hline Plástico & 0,382 & 12,09 & 1,168 & 21,31 & 0,868 & 16,73 & 0,398 & 9,88 & 0,580 & 14,90 & 3,396 & 15,61 \\
\hline Papel e papelão & 0,020 & 0,63 & - & - & 0,184 & 3,55 & 0,27 & 6,70 & 0,010 & 0,26 & 0,484 & 2,23 \\
\hline Vidro & - & - & - & - & - & - & - & - & - & - & - & - \\
\hline Metal não ferroso & - & - & 0,010 & 0,18 & - & - & - & - & 0,092 & 2,36 & 0,102 & 0,47 \\
\hline Madeira & - & - & - & - & - & - & - & - & - & - & - & - \\
\hline $\begin{array}{l}\text { Pano, trapo, couro } \\
\text { e borracha }\end{array}$ & - & - & 0,278 & 5,07 & 0,174 & 3,35 & 0,062 & 1,54 & 0,150 & 3,85 & 0,664 & 3,05 \\
\hline $\begin{array}{l}\text { Pedra, terra e } \\
\text { cerâmica }\end{array}$ & - & - & - & - & - & - & - & - & - & - & - & - \\
\hline Misto & 0,040 & 1,27 & 0,000 & - & 0,086 & 1,66 & 0,18 & 4,47 & 0,020 & 0,51 & 0,326 & 1,50 \\
\hline TOTAL & 3,160 & 100 & 5,480 & 100 & 5,188 & 100 & 4,030 & 100 & 3,892 & 100 & 21,750 & 100 \\
\hline $\begin{array}{l}\text { Número de alunos } \\
\text { presentes }\end{array}$ & 19 & - & 23 & - & 20 & - & 22 & - & 20 & - & 104 & - \\
\hline $\begin{array}{l}\text { Geração per capita } \\
\text { (kg/aluno.aula) }\end{array}$ & 0,166 & - & 0,238 & - & 0,259 & - & 0,183 & - & 0,195 & - & 0,209 & - \\
\hline
\end{tabular}

Fonte: As autoras (2017).

Ao longo dos cinco períodos de amostragem foi gerado um total de $21,750 \mathrm{~kg}$ de resíduos sólidos. A maior parte dos resíduos consiste de restos alimentares, identificados como matéria orgânica putrescível (77,14\%), seguido de plástico $(15,61 \%)$ e pano, trapo, couro e borracha $(3,05 \%)$. No dia 03/04 houve a maior geração de resíduos orgânicos, devido à quantidade significativa de creme e merengue que foi descartado. Já a menor geração foi registrada em 20/03, aula voltada principalmente ao preparo de massas, em que a quantidade de massa não aproveitada foi guardada para a aula seguinte. Sacos plásticos rígidos eram utilizados para armazenar as massas sob baixas temperaturas durante a aula. Logo, esse componente contribuiu para que a quantidade de plástico descartado fosse significativa, principalmente nos dias 03 e 10/04.

No que diz respeito à geração per capita, a mesma variou entre 0,166 a $0,259 \mathrm{~kg} /$ aluno.aula, representando uma média de $0,209 \mathrm{~kg} /$ aluno.aula. Constatou-se que não há uma proporcionalidade na relação entre a massa de resíduo gerado e o número de alunos presentes, levando-se em conta a configuração de trabalho em grupo. Além disso, o fato de haver receitas demonstrativas é uma condição que pode contribuir para que a geração per capita das aulas amostradas da disciplina de Confeitaria seja inferior ao determinado para as aulas de Cozinha das Américas.

Com relação aos resíduos que se encontravam acondicionados nos dispositivos instalados na cozinha para resíduo orgânico, a matéria orgânica putrescível representou 96,63\%, observando-se a mistura de materiais considerados recicláveis acondicionados junto aos resíduos orgânicos: plástico $(0,91 \%)$ e misto $(0,30 \%)$. Alguns estavam impregnados com alimento, enquanto outros apresentavam condições para reciclabilidade.

Entre os resíduos sólidos acondicionados no dispositivo para seletivos, verifica-se que o maior percentual corresponde ao plástico $(49,36 \%)$, seguido da matéria orgânica putrescível (32,39\%) e papel e papelão (7,33\%). Apesar do índice superior do plástico, a mistura de resíduos é considerável.

O Quadro 3 apresenta os exemplos de componentes observados nas caracterizações dos resíduos sólidos gerados nas aulas de Confeitaria, sendo possível observar quais resíduos foram acondicionados erroneamente. Constatou-se que guardanapos impregnados, papel manteiga e restos de alimentos, em menor quantidade, estavam presentes nos contêineres de resíduo seletivo. 
A quantidade de insumos necessária para cada aula também é solicitada pela professora diretamente à Escola. As receitas ministradas e o número de vezes que a mesma foi replicada foram fornecidos pela professora no final de cada aula.

O percentual do insumo fornecido em cada aula prática que foi convertido em resíduo variou de 22,69 a $34,52 \%$, em média de $28,87 \%$. Embora o índice esteja abaixo ao determinado para as aulas de Cozinha das Américas, o mesmo pode ser considerado significativo, pois de $75,338 \mathrm{~kg}$ de ingredientes fornecidos, $21,750 \mathrm{~kg}$ foram descartados como resíduo de preparo ou como prato não consumido. Houve casos em que os ingredientes utilizados para decoração na finalização das receitas não possuíam quantidade definida, seja na receita ou na listagem dos insumos. Portanto, não foram contabilizados no total de insumos utilizados.

Quadro 3 - Exemplos de componentes de resíduos sólidos observados nos contêineres nas aulas de Confeitaria

\begin{tabular}{|c|c|c|}
\hline \multirow{2}{*}{ CATEGORIAS } & \multicolumn{2}{|c|}{ Exemplos observados } \\
\hline & Contêiner orgânico & Contêiner seletivo \\
\hline $\begin{array}{l}\text { Matéria orgânica } \\
\text { putrescível }\end{array}$ & $\begin{array}{c}\text { Guardanapos impregnados com alimentos, } \\
\text { cascas de maçãa, miolo de maçãa, creme, } \\
\text { merengue, limão, casca de limão, massa } \\
\text { crua, papel manteiga impregnado, laranja, } \\
\text { amendoim, açúcar, biscoitos, casca de ovo, } \\
\text { chocolate derretido, plástico impregnado } \\
\text { com alimento, massa crua e assada e } \\
\text { recheio de doces }\end{array}$ & $\begin{array}{l}\text { Guardanapos impregnados com alimentos, } \\
\text { casca de ovo, maçã, papel manteiga, massas } \\
\text { assadas }\end{array}$ \\
\hline Plástico & Sacos e copos plásticos & $\begin{array}{l}\text { Sacos e copos plásticos, sacos plásticos de } \\
\text { massa, embalagem maionese, embalagem de } \\
\text { rolo de embalagem de alimento, recheador } \\
\text { de doces usado }\end{array}$ \\
\hline Papel e papelão & & $\begin{array}{l}\text { Rolo de papelão, embalagem de farinha } \\
\text { embalagem de ovos, papel com anotação, } \\
\text { caixa de papelão (embalagem de papel } \\
\text { manteiga) e folha de caderno }\end{array}$ \\
\hline Vidro & - & - \\
\hline Metal não ferroso & Papel alumínio & Papel alumínio \\
\hline Madeira & - & Palito de fósforo \\
\hline $\begin{array}{l}\text { Pano, trapo, } \\
\text { couro e borracha }\end{array}$ & Panos de limpeza e luvas & Panos de limpeza e luvas \\
\hline $\begin{array}{l}\text { Pedra, terra e } \\
\text { cerâmica }\end{array}$ & - & - \\
\hline Misto & Embalagens de manteiga & Caixas de leite e embalagens de manteiga \\
\hline
\end{tabular}

Fonte: As autoras (2017).

\section{SÍNTESE DOS RESULTADOS DA GERAÇÃO DE RESÍDUOS DAS AULAS PRÁTICAS DE COZINHA DAS AMÉRICAS E CONFEITARIA}

A partir das observações feitas durante as aulas e da avaliação dos resíduos sólidos gerados nas aulas práticas de Cozinha das Américas e de Confeitaria, verificou-se que se trata de culinárias distintas. Tal circunstância foi verificada pelos insumos utilizados e pelos resíduos gerados, bem como os pratos servidos e as respectivas sobras.
Foi constatada que a geração total de resíduos das aulas de Cozinha das Américas foi 3,15 vezes maior se comparada à geração correspondente às aulas de Confeitaria. Em relação à matéria orgânica putrescível, essa diferença é ainda maior: 3,72 vezes. Um dos motivos para esse fato é que a maior parte dos insumos utilizados na Confeitaria (farinha de trigo, açúcares, leite, manteiga, chocolate, creme de leite, entre outros) não apresenta perda durante o seu preparo. $\mathrm{Na}$ Cozinha das Américas, a maior parte dos insumos se trata de legumes, verduras, tubérculos, frutas, 
frutos do mar, carnes em geral, ovos, entre outros, resultando em perdas devido à manipulação. Tais perdas também foram observadas por Teichmann (2009).

Ademais, a praticidade do consumo dos pratos preparados pela Confeitaria, não necessitando de pratos e talheres, também pode contribuir para que a geração de resíduos seja inferior. Esse fato pode ser relacionado ao que Pistorello et al. (2015) constataram, que nos coffee-breaks (tipo de refeição que dispensa uso de pratos e talheres) foi obtido o maior índice de alimentos consumidos baseado na quantidade de alimentos ofertados se comparado às outras refeições servidas no hotel estudado.

Peruchin et al. (2013) observaram que a quantidade de resíduo gerado em cada dia abrangido pelo seu estudo não é proporcional ao número de refeições servidas, devido principalmente às mudanças diárias do cardápio do restaurante, o que envolve as particularidades dos ingredientes empregados. Pode-se considerar que esse fenômeno também ocorre em relação à geração per capita de ambas as disciplinas.

Copos e embalagens plásticas eram usualmente descartados junto ao resíduo orgânico, principalmente quando havia resto de insumos em seu interior. Em outros casos, há de se considerar a impregnação de alimentos junto a esses materiais, ocorrendo a mistura de categorias na massa de resíduos. Em pano, trapo, couro e borrachas, a maior parte era representada por panos descartáveis impregnados com alimentos, utilizados durante o preparo dos pratos e para a limpeza das bancadas. Isso justifica porque os percentuais dessa categoria $(3,13 \%$ em Cozinha das Américas e 3,05\% em Confeitaria) são representativos.

A falta de atenção e de conscientização durante a manipulação dos alimentos é responsável pela segregação e pelo acondicionamento incorreto dos resíduos (Corrêa \& Lange, 2011; Bradacz, 2003). Em relação à segregação dos resíduos, os papéis impregnados com alimento e/ou engordurados (papel toalha e papel manteiga) eram comumente encontrados nos contêineres de resíduo seletivo, devendo ser reforçada/esclarecida junto aos alunos a não condição de reciclabilidade desses materiais.

Também foi levantado que o número de receitas, bem como a variedade dos insumos envolvidos, denota no aumento da geração de resíduos (Pirani \& Arafat, 2014). Além disso, a inexperiência dos funcionários da cozinha em lidar com os alimentos, bem como o preparo de novas receitas, contribui com a geração de resíduos (Bradacz, 2003; Pirani \& Arafat, 2014; Tatàno et al., 2017). Esses fatos também ocorrem durante o processo de aprendizagem, conforme o observado na pesquisa na Escola.

A pressão à que os alunos são submetidos para que os pratos sejam finalizados no tempo da aula também pode reforçar essa geração, não permitindo que os mesmos sejam consumidos e, portanto, sejam descartados. Essa condição pode ser considerada análoga à constatada por Tatàno et al. (2017), na qual são previstos a redução da eficiência da segregação e o aumento da geração de resíduos em momentos em que a equipe do restaurante estudado está submetida "à pressão": preparar o alimento com tempo limitado.

\section{CONSIDERAÇÕES FINAIS}

O estudo demonstrou a representatividade da geração de resíduos sólidos na ocorrência de impactos ambientais em empreendimentos gastronômicos. Pode-se considerar que esse impacto é ainda maior em escolas de gastronomia, devido ao não direcionamento do alimento ao cliente, pois o foco das atividades exercidas é capacitar o aluno para o preparo dos pratos, e não ao atendimento ao consumidor. Por conseguinte, a geração de resíduos nesses empreendimentos advém principalmente dos alimentos preparados durante as atividades de ensino que ocorrem na Instituição.

Destaca-se que as peculiaridades das distintas atividades gastronômicas abrangidas nos diferentes estudos analisados podem influenciar os índices de geração per capita, bem como a representatividade das diferentes categorias de resíduos. Pistorello et al. (2015) investigaram o restaurante de um hotel, enquanto a pesquisa de Peruchin et al. (2013) foi realizada em um restaurante universitário.

A falta de uma segregação plenamente adequada durante as atividades faz com que se considere a necessidade de se realizar, continuamente, ações de sensibilização ambiental com alunos, professores, colaboradores e gestores, contemplando a temática dos resíduos. Essa medida se torna ainda mais necessária visto a rotatividade de funcionários, de alunos e docentes de outras cidades e estados, inclusive de outros países. Reitera-se, desse modo, a complexidade 
que envolve a geração e a gestão de resíduos nos empreendimentos gastronômicos.

O conhecimento prévio da temática dos resíduos sólidos gerados no serviço de alimentação possibilita que os alunos os considerem no planejamento de estabelecimentos que porventura venham a constituir ou gerir, perpassando pelo projeto arquitetônico, distribuição e organização dos setores, serviços disponibilizados e cardápios ofertados. O mesmo também pode tornar-se um aliado em relação à sustentabilidade do negócio, visto a economia de recursos como matéria-prima, água, energia, mão de obra e capital, contribuindo para a rentabilidade do mesmo e com o exercício de uma atividade econômica responsável sob as diferentes dimensões da sustentabilidade.

As oportunidades de melhoria identificadas a partir da decorrência do estudo são as seguintes, levando em conta, também, os preceitos da Produção Mais Limpa:

- Visto que a separação dos ingredientes é feita empregando os sacos e os copos plásticos descartáveis, pode-se considerar sua substituição por recipientes de material durável. Contudo essa medida demanda uma avaliação mais aprofundada, devido ao consequente aumento de consumo de água e produtos de limpeza, bem como o tempo demandado para o procedimento no final das atividades;

- Nas situações consideradas possíveis pelos docentes, pode-se promover a gradativa redução do porcionamento das receitas ministradas, tendo em vista a diminuição da geração de resíduos correspondentes aos pratos não consumidos e, ao mesmo tempo, a consonância da didática requerida para a aula prática;

- A adoção do procedimento de cálculo do Fator de Correção dos ingredientes, citado por Teichmann (2009), permite a previsão da quantidade de resíduos que será gerada. Além disso, o método possibilita que esse fator se configure como critério de escolha dos pratos, bem como a implantação de indicadores de geração de resíduos sólidos por culinária.

$\mathrm{Na}$ sistematização do conhecimento, deparouse com uma escassez, desatualização e, até mesmo, inconsistência de informações em algumas fontes, o que configurou uma limitação teórica, bem como a divergência quanto à padronização dos dados coletados e sistematizados entre os diferentes estudos. Ademais, não foram localizados referenciais que permitissem a comparação de dados referente à quantificação e à caracterização dos resíduos gerados em escolas de gastronomia.

Quanto à operacionalização da pesquisa, o fator limitante mais relevante foi com relação ao balanço mássico, pois as entradas (insumos a serem utilizados nas aulas práticas) não foram quantificadas, portanto não sendo possível identificar o percentual exato de insumosque foram convertidos em resíduos e, consequentemente, o aproveitamento dos mesmos. Ademais, durante as observações realizadas, verificou-se que parte das sobras era recolhida junto com os insumos remanescentes, sendo descartada na cozinha, ou seja, não contabilizada na caracterização.

Cabe destacar que, apesar das limitações para situar teoricamente pesquisas dessa natureza, julga-se que foram atingidos os objetivos inicialmente propostos. Como decorrência dos resultados obtidos, destacam-se algumas recomendações julgadas importantes de serem aplicadas em estabelecimentos gastronômicos.

A disponibilização do acesso a dados e informações acerca do desempenho ambiental dos empreendimentos pode estimular a necessária participação de todos os envolvidos. A gestão também deve proceder ao planejamento de longo prazo, incluindo, em eventuais projetos de construção, a reforma ou a ampliação da estrutura física, a concepção de espaços adequados e necessários à realização de todas as etapas do gerenciamento de resíduos.

Recomenda-se que, para estudos de caso, seja providenciada a quantificação dos insumos in natura, com o propósito de realizar o balanço mássico com maior exatidão. Tal investigação pode identificar falhas no preparo e no porcionamento dos pratos, bem como oportunidades de otimização do processo de aquisição dos insumos.

Em estudos futuros que abordarem a geração de resíduos em escolas de gastronomia, recomenda-se que a análise do resíduo gerado nas aulas práticas durante o preparo dos alimentos e dos pratos não consumidos seja realizada separadamente. Essa medida permite determinar o desperdício decorrente do excedente resultante 
da aula prática, bem como o aproveitamento dos alimentos, ou seja, a quantidade de insumos convertidos no produto final (pratos).

As limitações e as recomendações discorridas encaminham para a necessidade de novas e constantes pesquisas acerca da temática, no sentido de aumentar a produção e a socialização do conhecimento e internalizar os princípios do desenvolvimento sustentável nos serviços de alimentação.

Agradecimentos: Agradece-se ao Conselho Nacional de Pesquisa-CNPq pela bolsa de Iniciação à Pesquisa e bolsa de Produtividade em Pesquisa.

\section{REFERÊNCIAS}

Almeida, E. B. de, \& Hostins, R. C. L. (2011). O comportamento alimentar do turista e sua segurança no consumo de milho verde e churros à beira-mar. Revista Turismo Visão e Ação, 13(3), 347361. Recuperado de http://siaiap32.univali.br/seer/ index.php/rtva/article/view/2393/2072

Associação Brasileira de Normas Técnicas - ABNT (2004). NBR 10004: resíduos sólidos - classificação. Rio de Janeiro.

Associação Brasileira de Normas Técnicas - ABNT (2014). NBR 15401: meios de hospedagem - sistema de gestão da sustentabilidade - requisitos. Rio de Janeiro.

Agência Nacional de Vigilância Sanitária ANVISA, Resolução RDC $n^{\mathbf{o}}$ 216, de 15 de setembro de 2004. Recuperado de http://portal. anvisa.gov.br/documents/33916/388704/ RES O L U \% 25 C $3 \% 2587 \% 25$ C $3 \% 2583$ O RD C \% 2 B N \% 2 B $216 \% 2$ B DE $\% 2$ B $15 \% 2$ B DE \% 2 B S E T E M B R O \% 2 B D E \% 2 B 2004. pdf/23701496-925d-4d4d-99aa-9d479b316c4b

Bradacz, D. C. (2003). Modelo de gestão da qualidade para o controle de desperdício de alimentos em unidades de alimentação e nutrição (Dissertação de Mestrado em Engenharia de Produção, Universidade Federal de Santa Catarina, Florianópolis-SC, Brasil). Recuperado de http://repositorio.ufsc.br/bitstream/ handle/123456789/85188/225881.pdf?sequence $=1$

Brasil, Lei $n^{\circ}$ 12305. (2010). Dispõe sobre a Política Nacional de Resíduos Sólidos; altera a Lei no 9.605, de 12 de fevereiro de 1998; e dá outras providências. Recuperado de http://www.planalto. gov.br/ccivil_03/_ato2007-2010/2010/1ei/112305. htm

Centro Nacional de Tecnologias Limpas - CNTL. (2003). Implementação de Programas de Produção mais Limpa. Serviço Nacional de Aprendizagem Industrial - SENAI-RS Porto Alegre: CNTL, Recuperado de http://www.institutossenai.org.br/ public/files/manual_implementacao-pmaisl.pdf

Corrêa, M. da S., \& Lange, L. C. (2011). Gestão de resíduos sólidos no setor de refeição coletiva. Revista Pretexto, 12(1), 29-54. Recuperado de http://www. fumec.br/revistas/pretexto/article/view/659/566

De Conto, S. M. (2010). Gestão de resíduos em universidades: Uma complexa relação que se estabelece entre heterogeneidade de resíduos, gestão acadêmica e mudanças comportamentais. In: De Conto, S. M. (Org.), Gestão de resíduos em universidades (pp. 17-32). Caxias do Sul: Educs.

De Conto, S. M., Corrêa, L. B., \& Zaro, M. (2013). Empreendimentos turísticos e a geração de resíduos sólidos: A importância do planejamento de abrigos de armazenamento no projeto arquitetônico de meios de hospedagem. Caderno Virtual de Turismo, 13(3), 324-340. Recuperado de http:/www.ivt. coppe.ufrj.br/caderno/index.php?journal=caderno \&page $=$ article $\&$ op $=$ view $\&$ path $\% 5 B \% 5 \mathrm{D}=744 \& \mathrm{p}$ ath $\% 5 \mathrm{~B} \% 5 \mathrm{D}=376$

De Conto, S. M., Pessin, N., Pistorello, J., Zaro, M., \& Poletto, M. (2009). Geração de resíduos sólidos em um meio de hospedagem da Região Uva e Vinho no estado do Rio Grande do Sul. In: Anais... 25., Congresso Brasileiro de Engenharia Sanitária e Ambiental, 25., Recife. Rio de Janeiro: ABES, 2009. 1 CD-ROM.

Flores da Cunha. (2014). Plano municipal de gestão integrada de resíduos sólidos - PMGIRS. Recuperado de http://www.floresdacunha.rs.gov.br/conteudo/ plano-diretor--codigo-de-obras

Gândara, J. M. G. (2009). Reflexões sobre o turismo gastronômico na perspectiva da sociedade dos sonhos. In: Netto, A. P., Ansarah, M. G. dos R. (Org.), Segmentação do mercado turístico: estudos, produtos e perspectivas (pp. 179-194). Barueri, SP: Manole. Recuperado de https://ucs.bv3.digitalpages.com.br/ users/publications/9788520427071/pages/179

Krause, R. W., \& Bahls, A. A. D. S. M. (2013). Orientações gerais para uma gastronomia sustentável. Revista Turismo Visão e Ação, 15(3), 434450. Recuperado de http://siaiap32.univali.br/seer/ index.php/rtva/article/view/5119/2684

Köche, J. C. (2013). Fundamentos de metodologia científica: Teoria da ciência e iniciação à pesquisa. (33 ed.). Petrópolis, RJ: Vozes.

Mandelli, S. M. de C. (1997). Variáveis que interferem no comportamento da população urbana no manejo de resíduos sólidos domésticos no âmbito das residências (Tese de Doutorado em Educação, Universidade Federal de São Carlos, São Carlos, Brasil).

Marconi, M. A., Lakatos, E. M. (2008). Técnicas de pesquisa: planejamento e execução de pesquisas, amostragens e técnicas de pesquisa, elaboração, análise e interpretação de dados. (7 ed.). São Paulo, SP: Atlas.

Marconi, M. A., Lakatos, E. M. (2011). Metodologia científica. (6 ed.). São Paulo, SP: Atlas. 
Marques, V., Lopes, C. P., \& Claro, J. A. C dos S. (2012). A influência do Restaurante Manacá na gastronomia e sustentabilidade do bairro Camburi - São Sebastião - SP. Revista Turismo Visão e Ação, 14(1), 118-130. Recuperado de http://siaiap32.univali.br/ seer/index.php/rtva/article/view/1739/2170

Martínez, M. K. da S. (2012). Gastronomia e sustentabilidade: Um estudo da legislação ambiental e sanitária nos restaurantes de Macapá (Dissertação de Mestrado em Direito Ambiental e Políticas Públicas, Universidade Federal do Amapá, Macapá, Brasil). Recuperado de http:/www2.unifap.br/ ppgdapp/files/2013/05/MONNYA-KAROLLYNEDA-SILVA-MART\%C3\%8DNEZ.pdf

Mezomo, I. de B. (2015). Os serviços de alimentação: Planejamento e administração. (6 ed.). Barueri, SP: Manole. Recuperado de https:/ucsvirtual.ucs.br/ startservico/PEA/

Monteiro, J. H. P. et al. (2001). Manual de gerenciamento integrado de resíduos sólidos. Rio de Janeiro: Instituto Brasileiro de Administração Municipal - IBAM. Recuperado de http://www.ibam.org.br/media/ arquivos/estudos/manual_girs.pdf

Papargyropoulou, E., Wright, N., Lozano, R., Steinberger, J, Padfield, R., \& Ujang, Z. (2016). Conceptual framework for the study of food waste generation and prevention in the hospitality sector. Waste Management, 49, 326-336. doi: https://doi. org/10.1016/j.wasman.2016.01.017

Peruchin, B., Ferrão, A. L. L. da C., Guidoni, L. L. C., Corrêa, E. K., \& Corrêa, L. B. (2015). Estudo da geração dos resíduos sólidos em hotel. Revista Turismo Visão e Ação, 17(2), 301-322. Recuperado de http://siaiap32.univali.br/seer/index.php/rtva/ article/view/7954/4520

Peruchin, B., Guidoni, L. L. C., Corrêa, L. B., \& Corrêa, E. K. (2013). Gestão de resíduos sólidos em restaurante escola. Revista Tecno-lógica, 17(1), 13-23. Recuperado de https://online.unisc.br/seer/index. php/tecnologica/article/view/3627/2543

Pirani, S. I., \& Arafat, H. A. (2014). Solid waste management in the hospitality industry: A review. Journal of Environmental Management, 146, 320-336. doi: https://doi.org/10.1016/j.jenvman.2014.07.038

Pirani, S. I., \& Arafat, H. A. (2016). Reduction of food waste generation in the hospitality industry. Journal of Cleaner Production, 132, 129-145. doi: https://doi. org/10.1016/j.jclepro.2015.07.146

Pistorello, J., De Conto, S. M., \& Zaro, M. (2015). Geração de resíduos sólidos em um restaurante de um hotel da Serra Gaúcha, Rio Grande do Sul, Brasil. Revista Engenharia Sanitária e Ambiental, 20(3), 337-346. doi: http://dx.doi.org/10.1590/ S1413-41522015020000133231

Rubim, R. E. (2012). Consumo consciente e ético de alimentos na formação superior em Gastronomia - realidade e tendências em cursos de Tecnologia no Estado de São Paulo (Dissertação de Mestrado em Hospitalidade,
Universidade Anhembi Morumbi, São Paulo, Brasil). Recuperado de http://portal.anhembi.br/ dissertacoes/hospitalidade/programa-de-mestradoem-hospitalidade-dissertacoes-defendidas-2012/

Tatàno, F., Caramiello, C., Paolini, T., \& Tripolone, L. Generation and collection of restaurant waste: Characterization and evaluation at a case study in Italy. Waste Management, 61, 423-442. doi: https:// doi.org/10.1016/j.wasman.2017.01.020

Teichmann, I. M. (2009). Tecnologia culinária. (2 ed.). Caxias do Sul, RS: EDUCS.

Teixeira, S., Milet, Z., Carvalho, J., \& Biscontini, T. M. (2007). Administração aplicada às unidades de alimentação e nutrição. (1 ed.). São Paulo, SP: Atheneu.

Universidade de Caxias do Sul. (2014). Curso Superior de Tecnologia em Gastronomia - Projeto de Curso.

Universidade de Caxias do Sul. (2016). Escola de Gastronomia - Sobre a Escola. Recuperado de https://www.ucs.br/site/escola-de-gastronomia/ sobre-a-escola/

\section{Contribuição de cada autor na elaboração do artigo}

Maria Pires Prates: Introdução, revisão teórica, coleta de dados, sistematização dos resultados, conclusão.

Suzana Maria De Conto: Metodologia, coleta de dados, sistematização dos resultados, conclusão e revisão. 